ORIGINAL ARTICLE

\title{
Upper airway inflammation in waste handlers exposed to bioaerosols
}

\author{
K K Heldal, A S Halstensen, J Thorn, P Diupesland, I Wouters, W Eduard, \\ T S Halstensen
}

Occup Environ Med 2003;60:444-450

See end of article for authors' affiliations .....................

Correspondence to: Dr K K Heldal, National Institute of Occupational Health, PO Box 8149 , Dep., 0033 Oslo, Norway; kari.heldal@stami.no

Accepted

11 October 2002
A dverse health effects in workers involved in the household waste recycling industry were first described at a refuse plant in Denmark performing manual sorting of industrial and household waste. ${ }^{1}$ Initial symptoms of nose and eye irritation progressed to cases of organic dust toxic syndrome (ODTS), bronchial asthma, and chronic bronchitis in nine of 15 workers during the first year of work, presumably because of bioaerosol exposure from the waste. Some case reports also exist of allergic reactions such as hypersensitive pneumonitis after excessively high fungal spore exposure from wood chips and residential composting. ${ }^{23}$ The underlying mechanisms causing the reported health effects are still unclear, but there is increasing evidence that the respiratory symptoms caused by bioaerosol exposure are mainly of an non-allergic inflammatory nature.

Although exposure to high levels of bioaerosols liberated from waste and compost may induce respiratory diseases, it is uncertain to what degree moderate exposure levels, as during household waste collection, may be harmful. The bioaerosol produced from waste and compost is very complex and may contain bacteria and spores from bacteria and fungi. ${ }^{45}$ Their cell wall component endotoxins and $\beta(1 \rightarrow 3)$-glucans are capable of inducing inflammatory reactions. ${ }^{6-8}$ The exposure levels reported in these studies are in general moderate, compared to work environments such as farming, cotton mills, and sawmills. In particular, exposure levels of endotoxin, the most potent proinflammatory agent in the bioaerosol, were low.

Recently, acoustic rhinometry and nasal lavage (NAL) have been introduced as simple and non-invasive techniques to study acute inflammatory reactions in the upper airways. ${ }^{9}$ Acoustic rhinometry has been used successfully to measure the effect of irritants and allergens on mucosal swelling in the nose, ${ }^{10-12}$ but has until now not been used in field studies of waste handlers. It was recently reported that work related increased levels of neutrophils and myeloperoxidase (MPO) in the nasal lavage from waste collectors and compost workers were correlated to the endotoxin and dust. ${ }^{78}$ In an experimental study of waste handlers, intranasally challenged with compost dust and different microbial components, lipopolysaccharide (LPS) from endotoxin was the major inducer of nasal neutrophil influx and proinflammatory cytokine production, whereas $\beta(1 \rightarrow 3)$-glucan and compost dust induced only minor changes in the nasal lavage. Acoustic rhinometry measured 12 hours after challenge, revealed no swelling of mucosa. $^{10}$

Although these studies suggested that exposure to agents from waste may induce non-allergic reactions and subsequent symptoms in the airways, it is not known which of the microbial agents in the bioaerosol are important for development of the inflammation. The purpose of the present study was to assess the airway inflammation in waste handlers and to associate the response to the exposure to the different microbial agents.

\section{MATERIALS AND METHODS Population}

The survey was performed in workers at a waste company just outside Oslo where the separation of household waste with subsequent composting of the organic fraction was implemented in 1997. The company was chosen because of the nearby location to a hospital where health examination of the workers was performed. The survey took place in the summers

Abbreviations: ECP, eosinophilic cationic protein; EIA, enzyme immunoassay; IL, interleukin; LPS, lipopolysaccharide; MPO, myeloperoxidase; NAL, nasal lavage; ODTS, organic dust toxic syndrome 
Table 1 Characteristics of waste handlers

\begin{tabular}{|c|c|c|c|c|}
\hline & \multicolumn{4}{|c|}{ Characteristic } \\
\hline & $\mathrm{n}^{*}$ & Median & Range & $\%$ \\
\hline Gender, male & 31 & & & 97 \\
\hline Age, y & 31 & 32 & $18-58$ & \\
\hline Duration of employment, $y$ & 31 & 1.5 & $1-8$ & \\
\hline Atopy, Phadiatop positive & 22 & & & 36 \\
\hline \multicolumn{5}{|l|}{ Smoking } \\
\hline Current smokers & 31 & & & 87 \\
\hline Non-smokers $†$ & 31 & & & 13 \\
\hline Pack-years $\ddagger$ & 31 & 13 & $5-80$ & \\
\hline
\end{tabular}

Table 2 Exposure of waste handlers to bacteria, fungal spores, inhalable dust, endotoxins, and glucans (individual median exposure from Monday until Thursday and only on Wednesday are shown)

\begin{tabular}{|c|c|c|c|c|}
\hline \multirow[b]{3}{*}{ Exposure } & \multicolumn{4}{|c|}{ Exposure level } \\
\hline & \multicolumn{2}{|c|}{$\begin{array}{l}\text { Monday until Thursday, } \\
n^{*}=93\end{array}$} & \multicolumn{2}{|c|}{ Only Wednesday, $n=31$} \\
\hline & Median & Range & Median & Range \\
\hline Total bacteriat, $10^{6} / \mathrm{m}^{3}$ & 0.84 & $0.06-3.8$ & 0.89 & $0.03-4.2$ \\
\hline Rod shaped, $10^{6} / \mathrm{m}^{3}$ & 0.004 & $0-0.1$ & 0.006 & $0-0.2$ \\
\hline Spherical, $10^{6} / \mathrm{m}^{3}$ & 0.82 & $0.06-3.7$ & 0.81 & $0.03-4.2$ \\
\hline Actinomycetes spores, $10^{6} / \mathrm{m}^{3}$ & 0 & $0-1.1$ & 0 & $0-2.2$ \\
\hline Fungal spores, $10^{6} / \mathrm{m}^{3}$ & 0.17 & $0-2.0$ & 0.16 & $0-2.0$ \\
\hline Inhalable dust, $\mathrm{mg} / \mathrm{m}^{3}$ & 0.35 & $0.1-2.1$ & 0.30 & $0-6.6$ \\
\hline Endotoxins, $\mathrm{EU} / \mathrm{m}^{3}$ & 13 & $7-180$ & 18 & $4-180$ \\
\hline$\beta(1 \rightarrow 3)$-glucans, $\mathrm{ng} / \mathrm{m}^{3}$ & 40 & $3-220$ & 26 & $2-190$ \\
\hline
\end{tabular}

* Number of measurements.

†Total bacteria: spherical, rod shaped bacteria estimated by fluorescence microscopy, and actinomycetes spores estimated by scanning electron microscopy.

of 1999 and 2000. Table 1 shows descriptive characteristics of the workers. In total, 31 waste handlers voluntarily participated in the survey, 19 during the first year and 12 in the second year (84\% participation rate). The waste handlers comprised 25 waste collectors, of whom 22 collected organic waste and three collected paper waste, and six compost workers. No information on the non-responders was obtained. Twenty two workers (18 organic waste collectors and four compost workers) voluntarily accepted to be tested for respiratory allergens in serum (Phadiatop test, FEIA, UniCap system, Pharmacia Diagnostic AB, Uppsala, Sweden). The main tasks carried out by the waste collectors were emptying containers and truck driving. The organic fraction, mainly consisting of food and garden waste, was collected every fortnight. At the compost plant the main work tasks for the workers were process control, cleaning, maintenance, and repairing technical failures. Composting was performed indoors in open aerated bins. All participants gave their informed consent and the study was approved by the Regional Medical Ethics Board.

\section{Study design}

Nasal lavage samples were collected and acoustic rhinometry was performed before work started on Monday morning and on the following Thursday morning. Personal full shift exposure was monitored on Monday, Tuesday, and Wednesday. The workers were asked not to smoke one hour before the medical examination was performed. The participants completed a self administered questionnaire which included questions on upper airway symptoms which they had experienced on the day of exposure measurements. This questionnaire has previously been used in investigations of organic dust related effects. ${ }^{13}$

\section{Exposure measurements}

Samples were collected with two PAS-6 cassettes. One sample was collected on a polycarbonate filter (pore size $0.8 \mu \mathrm{m}$, Poretics, Osmonics, Livermore, USA) and analysed for dust by gravimetry, and bacteria, fungal, and bacterial spores by microscopic methods as described previously. ${ }^{14}{ }^{15}$ The second sample was collected on a glass fibre filter (Whatman GF/A, Maidstone, UK) for analysis of endotoxins and $\beta(1 \rightarrow 3)$ glucans by specific quantitative kinetic chromogenic Limulus amoebocyte lysate assays. ${ }^{16}$ By dividing this filter, the samples were also analysed for glucans by an inhibition enzyme immunoassay (EIA). ${ }^{18}$

\section{Acoustic rhinometry}

The nasal cavity dimensions were measured by acoustic rhinometry (Rhin2 100, Rhino Metrics AS, Lynge, Denmark) in a seated position, using a handheld sound wave tube and an anatomic nasal adapter. ${ }^{19}$ The mean of three independent measurements with a coefficient of variation $<5 \%$ were used for calculations. ${ }^{19}$ The total nasal volume and cross sectional areas were calculated as the sum of both nasal cavities, in order to minimise bias because of the nasal cycle. The smallest total cross sectional area and the total volume between $0-20$ $\mathrm{mm}$ (1) and 20-50 mm (2) from the nostrils were called TMCAl and TMCA2, and TVOL1 and TVOL2, respectively.

For each person, three series of measurements were performed, the first on Monday morning, the second on Thursday morning, and the third on Thursday morning 15 minutes after decongestion with xylometazoline. The degree of mucosal swelling was estimated from the decongestive effect. ${ }^{20}$ A decongestion factor was computed as follows: 
Table 3 Cells and inflammatory markers in nasal lavage fluid on Monday and Thursday

\begin{tabular}{|c|c|c|c|c|}
\hline \multirow[b]{2}{*}{ NAL parameters } & \multicolumn{2}{|c|}{ Monday } & \multicolumn{2}{|c|}{ Thursday } \\
\hline & $\mathrm{n} \dagger$ & Median (range) & $\mathrm{n}$ & Median (range) \\
\hline Total cells $\left(\times 10^{6} / \mathrm{ml}\right)$ & 29 & $0.174(0-2.39)$ & 29 & $0.138(0-1.30)$ \\
\hline Neutrophils $\left(\times 10^{6 / \mathrm{ml}}\right)$ & 28 & $0.040(0-0.93)$ & 26 & $0.067(0.01-0.69)$ \\
\hline Epithelial cells $\left(\times 10^{6} / \mathrm{ml}\right)$ & 28 & 0.105 (0-1.59) & 26 & $0.084(0-0.76)$ \\
\hline Eosinophils $\left(\times 10^{6} / \mathrm{ml}\right)$ & 28 & $0(0-0.01)$ & 26 & $0(0-0.02)$ \\
\hline Neutrophils (\%) & 29 & $28(4-92)$ & 28 & $46^{* * *}(7-86)$ \\
\hline Epithelial cells (\%) & 29 & $73(8-96)$ & 28 & 54 (14-94) \\
\hline Eosinophils (\%) & 29 & $0(0-1)$ & 28 & $0(0-3)$ \\
\hline IL-8 (pg/ml) & 30 & $651(0-3379)$ & 30 & $902(0-4749)$ \\
\hline MPO (ng/ml) & 30 & 210 (0-2394) & 30 & $330(21-2775)$ \\
\hline $\mathrm{ECP}(\mathrm{ng} / \mathrm{ml})$ & 30 & $5.1(<2 \ddagger-32.9)$ & 30 & $9.3^{*}(<2.0-47.6)$ \\
\hline
\end{tabular}

Table 4 Acoustic rhinometry results of 12 workers handling waste and compost

\begin{tabular}{|c|c|c|c|c|c|c|}
\hline & \multicolumn{2}{|l|}{ Monday } & \multicolumn{2}{|c|}{ Thursday } & \multicolumn{2}{|c|}{ Thursday after congestion } \\
\hline & Median & Range & Median & Range & Median & Range \\
\hline TMCAl, $\mathrm{cm}^{2}$ & 0.81 & $0.56-1.22$ & 0.73 & $0.52-1.28$ & 0.65 & $0.45-1.05$ \\
\hline TVOL $1, \mathrm{~cm}^{3}$ & 2.52 & $1.33-3.72$ & 2.51 & $1.84-3.24$ & 2.35 & $1.48-2.97$ \\
\hline TMCA2, $\mathrm{cm}^{2}$ & 0.98 & $0.44-1.23$ & 0.77 & $0.29-1.36$ & 0.96 & $0.49-1.63$ \\
\hline TVOL2, $\mathrm{cm}^{3}$ & 5.65 & $3.36-8.14$ & 5.30 & $2.38-6.93^{* *}$ & 7.83 & $4.24-11.39$ \\
\hline
\end{tabular}

** $p<0.05$ Thursday $v$ Monday (Mann-Whitney test).

TMCA 1: total minimum cross sectional area in the anterior $20 \mathrm{~mm}$ of the nasal cavity.

TVOL 1: total volume of the anterior $20 \mathrm{~mm}$ of the nasal cavity

TMCA2: total minimum cross sectional area between 20 and $50 \mathrm{~mm}$ from the nostril.

TVOL2: total volume of the area between 20 and $50 \mathrm{~mm}$ from the nostril.

$$
\begin{aligned}
& \text { Decongestion }_{\text {factor }}=1+\left(\mathrm{TVOL} 2_{\text {affer decongestion }}-\right. \\
& \text { TVOL2 } \left.{ }_{\text {before decongestion }}\right) / \mathrm{TVOL} 2_{\text {before decongestion }}
\end{aligned}
$$

\section{Nasal lavage}

Nasal lavage was performed and processed as previously described by Peden, with minor modifications. ${ }^{21}$ To resuspend cells trapped in mucus, $4 \mathrm{ml}$ of $0.1 \%$ dithiothreitol (DTT, Sigma Chemicals Co., St Louis, USA) in phosphate buffered saline was added per gram cell pellet. Cytocentrifuge prepared slides were stained with May-Grünwald-Giemsa stain and 400 cells were counted for cell differentials. The supernatants were used for measurements of inflammatory markers. The concentrations of IL- 8 and MPO were measured by enzyme linked immunosorbent assay (ELISA) (IL-8, MPO-EIA, R\&D Systems, UK); ECP was measured by a fluorescent enzyme immunoassay technique (CAP ECP FEIA, Pharmacia Diagnostics AB, Uppsala, Sweden). The concentrations were expressed as $\mathrm{pg} / \mathrm{ml}$ or $\mathrm{ng} / \mathrm{ml}$.

\section{Statistical analysis}

Exposure was estimated for each worker by the median exposure of Monday, Tuesday, and Wednesday, and of Wednesday alone. Non-parametric tests were used as the distributions of most variables were skewed to the right. The associations between continuous exposure variables were analysed by means of the Spearman rank correlation coefficient. Associations including variables with more than $50 \%$ of the values below the limit of detection (LOD) were not performed. Paired comparisons of the change in nasal lavage parameters and acoustic rhinometry data from Monday to Thursday were performed by Wilcoxon signed rank tests. The levels of nasal lavage parameters in workers with self reported upper airway symptoms at least on one day of exposure measurements, were compared to those without symptoms by the MannWhitney test. Statistical tests were considered statistically sig- nificant at $\mathrm{p} \leqslant 0.05$. Possible confounding by age was studied through the associations between age and exposure, and between age and nasal lavage parameters. For this purpose, age was dichotomised in approximately equal groups $(\leqslant 30$ years and $>30$ years). Separate analyses for subgroups of workers were conducted on organic waste collectors $(n=22)$, non-atopic workers $(n=14)$, and smokers $(n=27)$. Multiple regression analysis to adjust for influential factors was not attempted given the small size of the study.

\section{RESULTS}

In total 93 exposure measurements of each microbial agent and dust were performed (table 2 ). The results from $\beta(1 \rightarrow 3)$ glucan measurements by the inhibition immunoassay are not shown, as only a few samples were higher than the detection limit for the method. A slightly, but not significantly higher exposure level among organic waste collectors was observed (data not shown).

Table 3 presents the nasal lavage cell counts and concentrations of inflammatory markers. The mean recovery of the nasal lavage fluid was $5.8 \mathrm{ml}$ (range 3.2-9.0 ml). Three samples were discarded from the differential cell counts because of no observed cells in the lavage, or too many erythrocytes. One worker was not at work during the entire study period and was therefore excluded from the nasal lavage data analysis. The median percentage of neutrophils in nasal lavage increased significantly from Monday to Thursday. Although eosinophils were only occasionally found, the level of ECP increased significantly from Monday to Thursday. The increase of both ECP and MPO correlated with the increase in the percentage of neutrophils $\left(r_{\mathrm{s}}=0.71, \mathrm{p}<0.001\right.$ and $r_{\mathrm{s}}=0.38$, $\mathrm{p}<0.05$, respectively), while the increase in IL- 8 correlated with the increase in the neutrophil concentration $\left(r_{\mathrm{s}}=0.41\right.$, $\mathrm{p}<0.05)$. 

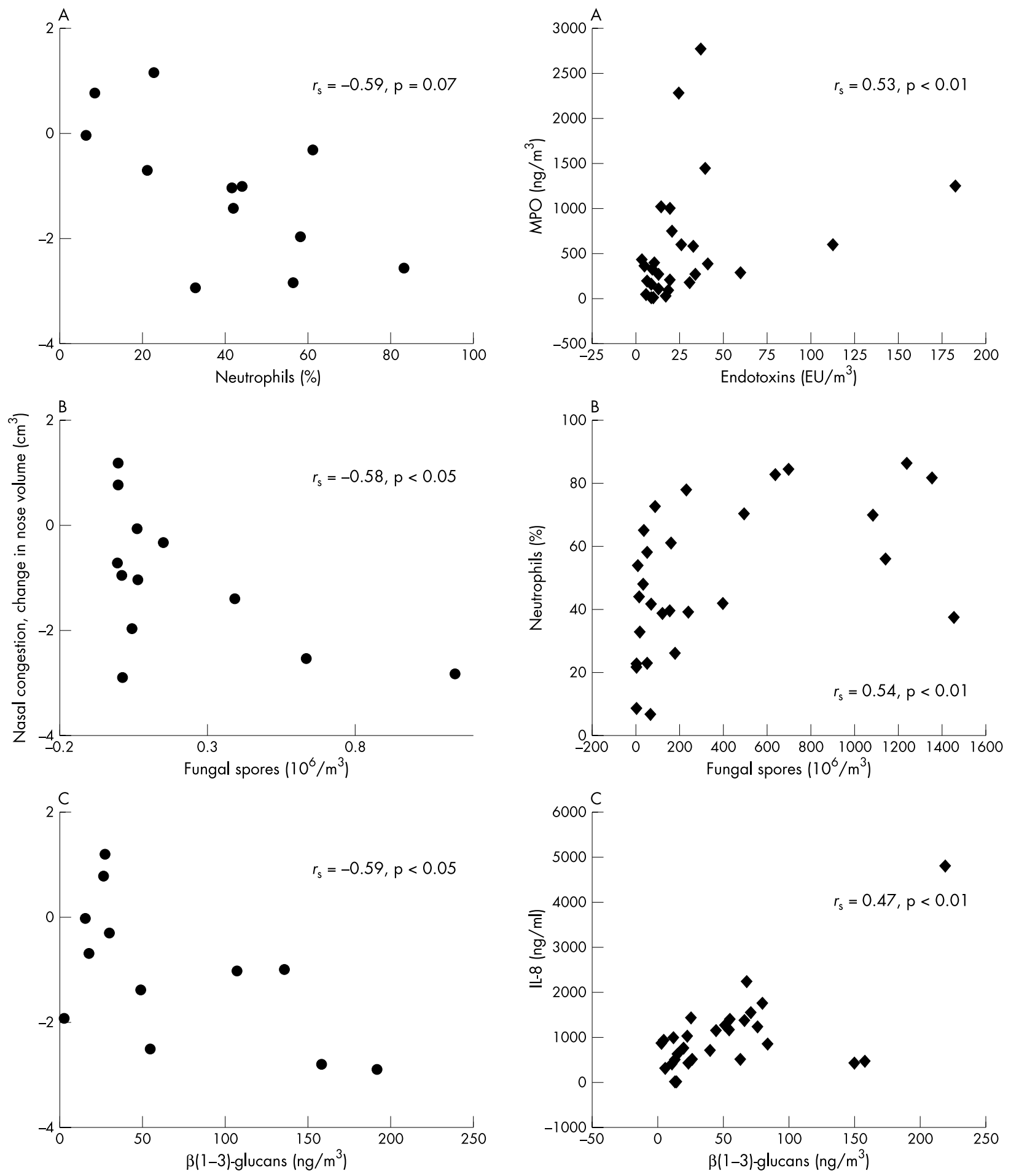

Figure 1 Acoustic rhinometry associations. Scatterplot of change in nasal congestion from Monday to Thursday and the increased level of neutrophils in nasal lavage $(A)$, exposure to fungal spores $(B)$, and $\beta(1 \rightarrow 3)$-glucan $(C)(n=12)$. The Spearman rank correlation coefficient is also given.

Valid measurements by acoustic rhinometry were only obtained from the 12 workers participating in the study in 2000 because of technical problems with the instrument during the first year of the study. The TVOL2 decreased significantly from Monday to Thursday $(\mathrm{n}=12$; median -1.0 $\mathrm{cm}^{3}$, range -2.9 to $+1.2 ; \mathrm{p}<0.05$ ) (table 4 ). TMCA2 decreased from Monday to Thursday (median $-0.1 \mathrm{~cm}^{2}$, range -0.5 to

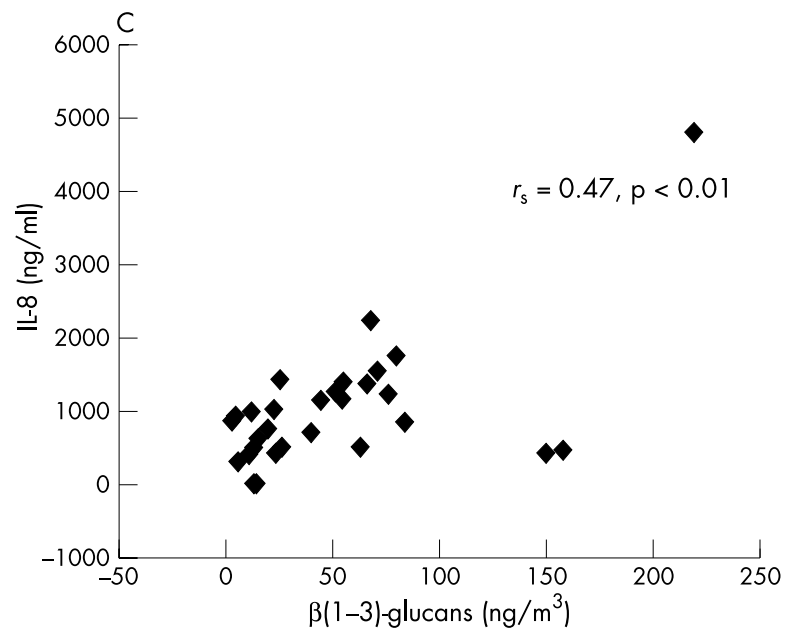

Figure 2 Nasal lavage associations. (A) Scatterplot of MPO measured on Thursday and the exposure to endotoxin measured the day before $(n=30)$. (B) Scatterplot of percentage neutrophils measured on Thursday and exposure to fungal spores measured the day before $(n=28)$. (C) Scatterplot of IL-8 measured on Thursday and the median $\beta(1 \rightarrow 3)$-glucan exposure $(n=30)$. The Spearman rank coefficient is also given.

significant association between the decrease in nose volume and differential counts of neutrophils after three days of exposure was found $\left(r_{\mathrm{s}}=-0.59, \mathrm{p}=0.07\right)$ (fig 1A). The median decongestion factor was 1.7 , with a range from 0.3 to 2.5 .

Thirteen per cent of the workers reported eye irritation, and $+0.1)$, but the change was not significant. A close to $20 \%$ reported nose irritation on one or on more than one day. 
Table 5 Correlations (Spearman) between inflammatory cells and mediators in nasal lavage fluid and exposure to microbial agents

\begin{tabular}{|c|c|c|c|c|c|c|c|c|}
\hline \multirow[b]{3}{*}{ Inflammatory markers } & \multicolumn{8}{|c|}{ Spearman rank correlation coefficient } \\
\hline & \multicolumn{4}{|c|}{ Wednesday exposure } & \multicolumn{4}{|c|}{ Median exposure } \\
\hline & Fungal spores & $\begin{array}{l}\beta(1 \rightarrow 3) \\
\text { glucans }\end{array}$ & Bacteria & Endotoxins & Fungal spores & $\begin{array}{l}\beta(1 \rightarrow 3) \\
\text { glucans }\end{array}$ & Bacteria & Endotoxins \\
\hline \multicolumn{9}{|l|}{ Thursday level of: } \\
\hline Neutrophils (\%) & $0.55^{* * *}$ & -0.09 & -0.20 & 0.03 & $0.54 * * *$ & 0.04 & -0.12 & -0.21 \\
\hline IL-8 (pg/ml) & -0.21 & 0.17 & 0.17 & 0.17 & -0.08 & $0.47 * * *$ & 0.10 & 0.07 \\
\hline $\mathrm{ECP}(\mathrm{ng} / \mathrm{ml})$ & 0.04 & -0.15 & 0.03 & 0.19 & 0.16 & 0.09 & 0.07 & 0.05 \\
\hline MPO (ng/ml) & -0.26 & 0.08 & 0.23 & $0.53^{* * *}$ & -0.11 & 0.09 & 0.12 & 0.30 \\
\hline \multicolumn{9}{|c|}{ Change from Monday to Thursday } \\
\hline Neutrophils (\%) & $0.33^{*}$ & 0.12 & 0.09 & -0.15 & 0.10 & 0.17 & 0.01 & $-0.42 * *$ \\
\hline Free IL8 (pg/ml) & -0.05 & 0.11 & -0.18 & -0.10 & -0.04 & $0.33^{*}$ & -0.07 & -0.13 \\
\hline $\mathrm{ECP}(\mathrm{ng} / \mathrm{ml})$ & 0.30 & -0.20 & 0.07 & 0.05 & 0.14 & 0.05 & 0.18 & -0.08 \\
\hline MPO (ng/ml) & 0.04 & -0.13 & -0.01 & 0.31 * & -0.10 & -0.16 & -0.06 & -0.07 \\
\hline
\end{tabular}

No associations between subjective symptoms and effect parameters in nasal lavage or acoustic rhinometry were observed.

The levels of cells and inflammatory markers measured in NAL on Thursday and the change from Monday to Thursday showed associations with both the median exposure of the three days and the exposure on Wednesday only (table 5). Thursday levels of MPO and percentage of neutrophils correlated with exposure to endotoxin and fungal spores, respectively, both measured on Wednesday (fig 2A,B), whereas the Thursday level of IL-8 correlated with the median $\beta(1 \rightarrow 3)$-glucan exposure (fig $2 \mathrm{C}$ ). Correlations between the changes in inflammatory markers from Monday to Thursday and exposure were weaker and not significant (table 5). Statistical testing using the cumulative exposure of the three days (mean concentration $\times$ duration of three work days) showed similar results as the median exposure (data not shown).

A significant correlation between nasal congestion and exposure to fungal spores and $\beta(1 \rightarrow 3)$-glucans on Wednesday was found (fig 1B,C). Exposure to spherical bacteria measured during work on Wednesday was associated with self reported nose irritation (median bacteria level $1.2 \times 10^{6} / \mathrm{m}^{3} v 0.6 \times 10^{6} /$ $\left.\mathrm{m}^{3}\right)$.

No major changes were observed when correlation analysis of subgroups of smokers only or non-atopics only were performed. Age had probably only a negative confounding effect on the associations as older workers had higher rates of nose irritation and nose congestion, but were less exposed to bacteria and fungal spores compared to younger workers. Age should therefore not confound the associations between inflammatory markers and exposure.

\section{DISCUSSION}

This study suggests that exposure to bioaerosols during waste handling induces upper respiratory inflammation dominated by a neutrophil infiltration and activation. The increase in neutrophils from Monday to Thursday correlated significantly with IL-8, MPO, and ECP in the NAL fluid, and almost significantly with the swelling of the nasal mucosa. The inflammatory response was probably associated with the exposure to microbial agents. The Thursday levels of MPO and neutrophils showed correlation with the exposure to fungal spores and endotoxin, respectively, measured on the day before, whereas IL-8 correlated with the median exposure to $\beta(1 \rightarrow 3)$-glucan. Furthermore, the swelling in the nasal mucosa on Thursday correlated with fungal spores and $\beta(1 \rightarrow 3)$-glucan exposure measured the day before. The correlations between inflammatory reactions and exposure measured on Wednesday seemed to be stronger than correlations with the median or cumulative exposure measurements, indicating that the observed effect probably occurs within a day.

No major changes were observed when associations were limited to smokers only. As only a few workers were non-smokers, the findings may only be valid for the smoking workers. Multiple testing may explain some of the associations between exposure and effects as 96 associations were tested. One of the associations is likely to be statistically significant at the 0.01 level, just as a result of chance. However, three associations with $\mathrm{p}<0.01$ were found, which suggests that most of the associations cannot be regarded as chance observations.

The increase of neutrophils measured in NAL may be a result of an attractant effect of IL-8. Activated neutrophils are also major producers of IL-8 and MPO. The relation between the increase in concentration and percentage of neutrophils and the increases in IL-8 and MPO, respectively, may reflect the influx and activation of neutrophils into the upper airways. Similar results were reported recently in nasal lavage from waste collectors ${ }^{8}$ and compost workers. ${ }^{7}$ This influx may be a rather rapid response as 15 minutes of nasal LPS challenge in garbage workers lead to increased concentrations of neutrophils in the NAL after six hours. ${ }^{10}$

The upper airways inflammation was dominated by neutrophils; eosinophils were only occasionally observed. However, an increase of ECP (which is considered to be a specific measure of eosinophilic activity) was observed, but it was associated with the percentage of neutrophils rather than eosinophils. Neutrophils contain less than $1 \%$ of the amount of ECP that eosinophils do. ${ }^{22}$ It is therefore possible that the increased concentration of ECP in the NAL actually derived from neutrophils. Similar correlations have been reported in NAL in healthy volunteers ${ }^{23}$ and in induced sputum after LPS challenge. ${ }^{24}$ The effects found in NAL therefore suggest that an influx of neutrophils may be mediated by the chemokine IL-8 followed by neutrophil activation.

An inflammatory reaction in the airways of waste handlers was further supported by swelling of the nasal mucosa, which also showed a close to significant correlation with the neutrophil influx. The median decongestion factor of 1.65 was higher than in normal subjects $(1.20-1.30),{ }^{20}$ but only one worker reported a subjective feeling of nasal congestion.

Although several agents may contribute to the observed inflammatory reaction, the fungal spores and $\beta(1 \rightarrow 3)$-glucans were presumably important as exposure levels correlated with the increase in neutrophils and IL-8 in NAL (fig 2B,C), as well as with the swelling of the nasal mucosa (fig $1 \mathrm{~B}, \mathrm{C}) . \beta(1 \rightarrow 3)$ glucans can initiate a variety of biological responses and may play a role in bioaerosol induced inflammatory responses. ${ }^{25}$ 
Main messages

- Waste handlers are exposed to bioaerosols when collecting and composting household waste. The exposure levels of bacteria, fungal spores, glucans, and endotoxins are moderate compared to working populations as farmers, cotton workers, and sewage workers where health effects are reported after bioaerosol exposure.

- An upper respiratory inflammation after three days of work was shown by an increase in neutrophils associated with the inflammatory enzymes myeloperoxidase (MPO) and eosinophil cationic protein (ECP). The inflammatory response in the upper airway was confirmed by increased swelling of the nasal mucosa.

- The exposure to bioaerosols during work is the most likely cause of the upper respiratory inflammation as associations between the inflammatory response and various agents in the bioaerosol were indicated. Exposure to fungal spores and $\beta(1 \rightarrow 3)$-glucans showed a more pronounced association with the nasal swelling and neutrophil influx than endotoxin.

\section{Policy implications}

- Exposure during waste handling induces acute upper respiratory inflammation, measurable in nasal lavage and by acoustic rhinometry. The implications of chronic inflammation in the nose with subsequently nasal symptoms and diseases are not yet known and should be the subject of further research.

$\beta(1 \rightarrow 3)$-glucans have been shown to activate neutrophils, ${ }^{26}$ but no association was observed between neutrophil influx and glucan exposure in compost workers and waste collectors. ${ }^{78}$ Other cells may be influenced as the concentration of blood lymphocytes was reported to be dose related to $\beta(1 \rightarrow 3)$-glucan exposure (range $10-36 \mathrm{ng} / \mathrm{m}^{3}$ ) in Swedish waste collectors. ${ }^{6}$ Moreover, nasal challenge of $\beta(1 \rightarrow 3)$ glucans in waste handlers, induced primarily increases in serum IL-8 and only minor changes in NAL IL-8 concentration.

The use of acoustic rhinometry to study nasal swelling in field studies of waste collectors has not previously been reported. However, mucosal swelling have been reported after exposure to microbial agents in other populations such as swine confinement workers ${ }^{11}$ and wood workers. ${ }^{12}$ Results from these field studies are contrary to findings in an experimental study, where garbage workers were intranasally challenged with aqueous extracts of endotoxin, a $\beta(1 \rightarrow 3)$ glucan (curdlan), Aspergillus fumigatus spores, and compost for 15 minutes. $^{10}$ Curdlan and A fumigatus spores as well as compost were able to induce an increase in total nose volume. The authors explained their findings by a possible release of vasoactive cytokines, leading to an influx of neutrophils during the following 12-18 hours after challenge, and a lower total nose volume later. Exposure to aqueous extracts instead of airborne particles may also have influenced the results.

Glucans may be regarded as an environmental marker for fungi, although glucans may also be present in some bacteria and plants. As the correlation between exposure to fungal spores and $\beta(1 \rightarrow 3)$-glucans in the present study was weak, these exposures may be regarded as independent factors. The present study therefore gives some support to an inflammatory effect from $\beta(1 \rightarrow 3)$-glucan exposure independent from fungal spores.

The exposure to endotoxin on Wednesday showed associations with the concentration of MPO in NAL on the following day (fig 2A), although the exposure levels were relatively low. Endotoxin is the most widely studied bioaerosol component, and is regarded as a potent inducer of non-allergic inflammatory reactions. Inhalation of endotoxin induces acute influx of neutrophils, a low level of eosinophils, and increased production of proinflammatory cytokines (IL-1, IL-6, TNF- $\alpha$, IL-8) and MPO reflected in airway fluids. ${ }^{27}$ The concentration of IL-8 and MPO in NAL from waste collectors and compost workers was recently reported to be associated with low endotoxins exposure. $^{78}$ Synergistic effects between endotoxin and $\beta(1 \rightarrow 3)$-glucans have been shown in animal studies ${ }^{28}$ and between fungal spores and endotoxin in an vitro study. ${ }^{29}$ It can therefore not be excluded that endotoxin, even at the low levels observed here, may contribute to the inflammatory response.

The present study is based on a relatively small population, and conclusions must be drawn with care. However, the results suggested that moderate exposure to fungal spores and $\beta(1 \rightarrow 3)$-glucans, and even low exposure to endotoxin during waste handling, induced upper airway inflammation characterised by neutrophil influx and activation (MPO, ECP, IL-8). The nasal inflammation was confirmed by swelling and subsequent response to a decongestant. The inflammatory reaction was associated with the exposure of various microbial agents in the bioaerosol, but in a complex manner.

\section{Authors' affiliations}

K K Heldal, A S Halstensen, W Eduard, National Institute of

Occupational Health, Oslo, Norway

J Thorn, Department of Environmental Medicine, Gothenburg University, Sweden

P Djupesland, Department of Otorhinolaryngology, Ullevål University Hospital, Oslo, Norway

I Wouters, Institute of Risk Assessment Science, Division of Environmenta \& Occupational Health, University of Utrecht, Netherlands

T S Halstensen, Institute of Oral Biology, University of Oslo, Norway

\section{REFERENCES}

1 Sigsgaard T, Bach B, Malmros P. Respiratory impairment among workers in a garbage-handling plant. Am J Ind Med 1990;1:92-3.

2 Weber S, Kullman G, Petsonk E, et al. Organic dust exposures from compost handling: case presentation and respiratory exposure assessment. Am J Ind Med 1993;24:365-74.

3 Brown JE, Masood D, Couser Jl, et al. Hypersensitivity pneumonitis from residential composting: residential composter's lung. Ann Allergy Asthma Immunol 1995;74;45-7

4 Nielsen EM, Nielsen BH, Breum ON. Occupational bioaerosol exposure during collection of household waste. Ann Agric Environ Med 1995:2:53-9.

5 Heldal K, Eduard W, Bergum M. Bioaerosol exposure during handling of source separated household waste. Ann Agric Environ Med 1997;4:45-51

6 Thorn J, Beijer L, Rylander R. Airways inflammation and glucan exposure among household waste collectors. Am J Ind Med 1998;33:463-70

7 Douwes J, Dubbeld H, van Zwieten L, et al. Upper airway inflammation assessed by nasal lavage in compost workers: a relation with bioaerosol exposure. Am J Ind Med 2000:37:459-68.

8 Wouters IM, Hilhorst SK, Kleppe $\mathrm{P}$, et al. Upper airway inflammation and respiratory symptoms in domestic waste collectors. Occup Environ Med 2002;59:106-12.

9 Steerenberg PA, Fischer PH, Gmelig MF, et al. Nasal lavage as tool for health assessment of photochemical air pollution. Hum Exp Toxicol 1996;15:111-19.

10 Sigsgaard T, Bonefeld-Jørgensen EC, Kiærgaard SK, et al. Cyłokine release from the nasal mucosa and whole blood after experimental exposures to organic dust. Eur Respir J 2000;16:140-5.

11 Larsson BM, Palmberg L, Malmberg PO, et al. Effect of exposure to swine dust on levels of IL-8 in airway lavage fluid. Thorax 1997;52:638-42

12 Schlünssen V, Schaumburg I, Andersen NT, et al. Nasal patency is related to dust exposure in wood workers. Occup Environ Med 2002:59:23-9.

13 Melbostad E, Eduard W. Organic dust-related respiratory and eye irritation in Norwegian farmers. Am J Ind Med 2001;39:209-17.

14 Eduard W, Sandven P, Johansen B, et al. Identification and quantification of mould spores by scanning electron microscopy (SEM). Ann Occup Hyg 1988;32:447-55.

15 Heldal K, Skogstad A, Eduard W. Improvements in the quantification of airborne microorganisms in the farm environment by epifluorescence microscopy. Ann Occup Hyg 1996;4:437-47.

16 Douwes J, Versloot P, Hollander A, et al. Influence of various dust sampling and extraction methods on the measurement of endotoxin. Appl Environ Microbiol 1995;61:1763-9. 
17 Tamura $\mathrm{H}$, Arimoto $\mathrm{Y}$, Tanaka $\mathrm{S}$, et al. Automated kinetic assay for endotoxin and (1 $\rightarrow 3)$ - $\beta$-D-glucan in human blood. Clin Chem Acta 1994;226:109-12

18 Douwes J, Doekes G, Montijn R, et al. Measurement of $\beta(1-3)$-glucans in the occupational and home environment with an inhibition enzyme immunoassay. Appl Environ Microbiol 1996;62:3176-82.

19 Anon. Acoustic rhinometry-standardisation and use. Rhinology 2000; (suppl 16)

20 Taverner D, Blickfor L, Shaib S, et al. Evaluation of the dose-response relationship for intra-nasal oxymetazoline hydrochloride in normal adults. Eur J Clin Pharmacol 1999:55:509-13.

21 Peden DB. The use of nasal lavage for objective measurement of irritant-induced nasal inflammation. Regul Toxicol Pharmacol 1996;24:76-8.

22 Venge P. Soluble markers of allergic inflammation. Allergy 1994:49:1-8.

23 Steerenberg PA, Fischer PH, Gmelig MF, et al. Nasal lavage as tool for health assessment of photochemical air pollution. Hum Exp Toxicol 1996:15:111-19.
24 Thorn J, Rylander R. Inflammatory response after inhalation of bacterial endotoxin assessed by the induced sputum technique. Thorax 1998;53: 1047-52.

25 Rylander $\mathbf{R}$. Investigation of the relationship between disease and airborne ( $1 \rightarrow 3$ )- $\beta$-D-glucan in buildings. Mediators Inflamm 1997;6:275-7.

26 Zhang K, Petty HR. Influence of polysaccharides on neutrophil function: specific antagonists suggest a model for cooperative saccharide-associated inhibition of immune complex-triggered superoxide production. J Cell Biochem 1994;56:225-35.

27 Thorn J. The inflammatory response in humans after inhalation of bacterial endotoxin: a review. Inflamm Res 2001;50:254-61.

28 Fogelmark B., Sjöstrand M, Rylander R. Pulmonary inflammation induced by repeated inhalation of $\beta(1 \rightarrow 3)$-glucan and endotoxin. Int $J$ Exp Pathol 1994:74:85-90.

29 Shahan TA, Sorenson WG, Lewis DM. Superoxide anion production in response to bacterial lipopolysaccharide and fungal spores implicated in organic dust toxic syndrome. Environ Res 1994;67:98-107.

\section{Politicians must protect populations from persistent organic pollutants}

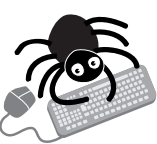

Please visit the Occupational and

Environmental website [www. occenvmed.com for link to these full articles.
Dersistent organic pollutants (POPs) in food are a worldwide problem demanding urgent worldwide government action, say the authors of a study in the US.

The authors analysed data held by the FDA, looking for the 12 most dangerous POPs listed for phasing out by the Stockholm Convention: residues of all 12 were in all food types-fruit and vegetables, meat, poultry, and dairy and baked foods. They estimated that, at worst, adults could be exposed to 63 to 70 daily "hits" by these residues, depending on where in the US they lived-north east, south east, western states, or the Midwest. The amounts present were above thresholds considered safe for adults for individual POPs and way above thresholds for children, whose sensitivity to POPs is greater. This despite bans on POPs in the US decades ago.

POPs are linked to cancer, learning disorders, impaired immunity, and reproductive disorders, and since their use surveillance studies have reported increases in them all. The evidence is that POPs-even in tiny amounts-are a serious health hazard.

POPs comprise organochlorine pesticides-DDT, dieldrin - industrial chemicals or process byproducts-PCBs, dioxins. The danger lies in their longevity, accumulation in food chains, and ability to spread far and wide in water and within air currents; POPs occur in human blood and breast milk around the world.

The Stockholm Convention was set up in May 2001 to stop the use of POPs. Fifty ratifications of the treaty are needed for it to take effect; by April 2002 just five governments had signed up. Other governments need to catch up-fast.

A Journal of Epidemiology and Community Health 2002;56:813-817.

\section{Past experience is a prophesy for the future}

7

wo American authors argue that effort now and in future should concentrate on banning production of all POPs, not debating the exact risks to human health from residues in food.

Recent data show that since bans and controls on the use of POPs such as dieldrin, amounts in human breast milk have fallen over the years. What is also clear is a historical pattern to the discovery of the detrimental effects of well known POPs suspected of being harmful. The effects of PCBs and their true toxicity to the developing human fetus have been appreciated only after decades of research in a succession of increasingly sensitive animal models and is now established at a millionth of the dose determined in the earliest animal model. Similarly, it has taken the US Environmental Protection Agency 20 years to conclude that dioxin is so toxic that no safe level exists. Recent results have shown that dieldrin residues in fat in women are linked to risk of breast cancer, with only slightly larger amounts increasing the risk of the cancer, of aggressive tumours, and of dying.

The historical angle, therefore, provides all the evidence we need: if new compounds are persistent, lipophilic, and accumulate in tissues and the environment then we should act now to rid our environment of them, the authors say. The first candidates should be polybrominated diphenyl ethers, widely used as flame retardants, and synthetic musks.

$\Delta$ Journal of Epidemiology and Community Health 2002;56:826-827. 